\title{
Lithium-Ion Batteries Anodic Performance of Porous Sn/C-ZnO Core-Shell Structures Derived from ZIF-8
}

\author{
Shouhui Chen", Rihui Zhou, Yaqin Chen, Ping Li, Yonghai Song and Li Wang \\ College of Chemistry and Chemical Engineering, Jiangxi Normal University, 99 Ziyang Road, \\ Nanchang 330022, People's Republic of China \\ *E-mail: csh2k@sina.com
}

doi: $10.20964 / 2016.12 .62$

Received: 17 September 2016 / Accepted: 21 October 2016 / Published: 10 November 2016

\begin{abstract}
Zeolitic imidazolate frameworks are a class of metal organic frameworks which are very attractive for their pore structures. However, their pore size and the BET surface would shrink when they underwent heat treatment at high temperature. On the other hand, liquid metal in MOFs might flow through the pores and prevent the shrinkage when pyrolysis. As is known that metallic $\mathrm{Sn}$ is liquid when the temperature is above $232{ }^{\circ} \mathrm{C}$, flowing Sn might support and maintain the porous structure of MOFs during the pyrolysis. In this work, porous $\mathrm{Sn} / \mathrm{C}-\mathrm{ZnO}$ core-shell structures were prepared as anodes for LIBs via a two-step method. Firstly, $\mathrm{SnO}_{2}$ particles were encapsulated in a ZIF-8 layer with different thickness. Then $\mathrm{Sn} / \mathrm{C}-\mathrm{ZnO}$ was generated in inert atmosphere at $700{ }^{\circ} \mathrm{C}$. A Sn/C-ZnO composite, with $11.2 \%$ of $\mathrm{Sn}$ and $21.0 \%$ of $\mathrm{ZnO}$ in content, had a BET surface of $32.9 \mathrm{~m}^{2} \mathrm{~g}^{-1}$. Another $\mathrm{Sn} / \mathrm{C}-\mathrm{ZnO}$ composite, with $55.1 \%$ of $\mathrm{Sn}$ and $1.8 \%$ of $\mathrm{ZnO}$ in content, had a larger BET surface of $297 \mathrm{~m}^{2} \mathrm{~g}^{-1}$. Then the two composites were tested as anodes for LIBs. Although the BET surface of the former was significantly less than that of the latter before cycling and the content of $\mathrm{Sn}$ in the former was also much lower than that of the latter, the discharge capacity of the former after 50 cycles was $515.6 \mathrm{mAh}$ $\mathrm{g}^{-1}$ at $100 \mathrm{~mA} \mathrm{~g}^{-1}$ in the potential of $0.01 \sim 3.00 \mathrm{~V}$, which was slightly higher than that of the latter.
\end{abstract}

Keywords: Lithium-ion batteries; anode; MOFs; metallic Sn; core-shell structure

\section{FULL TEXT}

(C) 2016 The Authors. Published by ESG (www.electrochemsci.org). This article is an open access article distributed under the terms and conditions of the Creative Commons Attribution license (http://creativecommons.org/licenses/by/4.0/). 